\title{
Los embelecos de la gramática: lengua, literatura y herejías gramaticales en la obra de Fernando Vallejo
}

The deceit of grammar: Language, literature, and grammar heresies in the work of Fernando Vallejo

Os embelecos da gramática: Língua, literatura, e heresias gramaticais na obra de Fernando Vallejo

\section{María Ospina}

WESLEYAN UNIVERSITY, ESTADOS UNIDOS

Profesora del Departamento de Literaturas y Lenguajes Romances en Wesleyan University. PhD en Literatura, Harvard University, Estados Unidos. Autora de "Naturalezas de guerra: topografías violentas de la selva en la narrativa colombiana contemporánea", en Revista de Crítica Literaria Latinoamericana (2014); "Trazados peligrosos: topografías contemporáneas de selva en relatos colombianos de cautiverio", en Geografías imaginarias: espacios de resistencia y crisis en América Latina, editado por Marta Sierra (Cuarto Propio, 2013); “"El Colombian Dream' y los sueños de un nuevo cine colombiano", Revista de Estudios Colombianos, 33-34 (2009); "Sobre envíos epistolares y violencias: de cómo se cultiva la persistencia en Colombia", ReVista. Harvard Review of Latin America (Spring 2008). Correo electrónico: mospina@wesleyan.edu

Artículo de reflexión

Documento accesible en línea desde la siguiente dirección: http://revistas.javeriana.edu.co 


\section{Resumen}

De la importancia de las reflexiones de Vallejo en torno a la gramática - uno de los discursos predominantes en su obra - se ocupa María Ospina en el presente artículo. A partir de una lectura de La virgen de los sicarios y El cuervo blanco (la biografía de Rufino José Cuervo que publicó Vallejo en el 2012), Ospina evalúa la centralidad de la gramática para el proyecto literario de Vallejo y su concepción de rol de la literatura en la Colombia contemporánea. La labor desestabilizadora de Vallejo, su interés por capturar los giros de la lengua hablada y de desafiar los rígidos límites de la gramática resultan, según Ospina, en una defensa de la producción estética y literaria como un lugar para la documentación del "paso del río cambiante del lenguaje" y la reflexión sobre el devenir histórico.

Palabras clave: Fernando Vallejo; La virgen de los sicarios; El cuervo blanco; biografía; estructuralismo lingüístico

\section{Abstract}

María Ospina deals with the importance of Vallejo's reflections about grammar-one of the predominant discourses of his work. From a reading of $L a$ virgen de los sicarios and $E l$ cuervo blanco (the biography of Rufino José Cuervo published by Vallejo in 2012), Ospina evaluates the centrality of grammar within Vallejo's literary project, and his concept about the role of literature in contemporary Colombia. By focusing on the questions and contradictions that surround the appropriation of the nineteenth-century figure of the grammarian by Vallejo, Ospina suggests that both the novel and biography question the authority and the scope of the prescriptive effort of the knowledge upon which the basis of an excluding society was built in Colombia. The destabilizing work of Vallejo, his interest in capturing the expressions of the spoken language and in challenging the rigid limits of grammar become, according to Ospina, a defense of the aesthetic and literary production, as a place for documenting the "crossing of the changing river of language" and the reflection on the evolution of history.

Key words: Fernando Vallejo; La virgen de los sicarios; El cuervo blanco; biography; linguistic structuralism

\section{Resumo}

María Ospina se ocupa, no presente artigo, da importância das reflexões de Vallejo em torno da gramática - um dos discursos predominantes em sua obra. A partir de uma aguda leitura de La Virgen de los sicarios e El cuervo blanco (a biografia de Rufino José Cuervo que Vallejo publicou em 2012), Ospina avalia a centralidade da gramática para o projeto literário do autor e sua concepção de rol da literatura na Colômbia contemporânea. Enfocando-se nos questionamentos e contradições que rodeiam a apropriação da figura decimônica do gramático por parte de Vallejo, Ospina argumenta que tanto o romance quanto a biografia questionam a autoridade e o alcance do esforço prescritivo do saber sobre o qual se construíram as bases de uma sociedade excludente na Colômbia. O trabalho desestabilizador de Vallejo, e seu interesse por capturar os meandros da língua falada e de desafiar os rígidos limites da gramática resultam, segundo Ospina, em uma defesa da produção estética e literária como um lugar para a documentação do "paso del río cambiante del lenguaje" e a reflexão sobre o devir histórico.

Palavras-chave: Fernando Vallejo; La virgen de los sicários; El cuervo blanco; biografia; estruturalismo linguístico

RECIBIDO: 1 DE JULIO DE 2014. EVALUADO: 22 DE JULIO DE 2014. DISPONIBLE EN LíNEA: 15 DE ENERO DE 2015.

Cómo citar este artículo:

Ospina, María. "Los embelecos de la gramática: lengua, literatura y herejías gramaticales en la obra de Fernando Vallejo". Cuadernos de Literatura 79,37 (2015): 247-273. doi:10.11144/Javeriana.CL19-37.ledg 
“Maldita sea la gramática! [...]Para [Andrés] Bello "la gramática de una lengua es el arte de hablarla correctamente, esto es, conforme al buen uso, que es el de la gente educada". ${ }_{\mathrm{c}} \mathrm{Un}$ arte? ¿Como la música pues? La gramática, don Andrés, no es un arte: es una pseudociencia como la ontología, la teología, la astrología, la frenología, el psicoanálisis... Es un ejercicio de la mente ociosa, una pestilencia de las neuronas. [... $]_{\mathrm{C}} \mathrm{Y}$ cuál es la "gente educada”? ${ }_{\mathrm{C}}$ El presidente? “ El cuervo blanco

LA GRAMÁTiCA, SABER que ha estado íntimamente ligado al ejercicio del poder político en Hispanoamérica desde tiempos coloniales, ocupa un lugar central dentro de las reflexiones lingüísticas, literarias y políticas de Fernando Vallejo. Desde su tratado de gramática del lenguaje literario, Logoi (1983), pasando por su ya canónica novela La virgen de los sicarios (1994) donde un gramático homosexual retorna del exilio a narrar sus travesías topográficas y lingüísticas por la convulsionada Medellín de los años noventa, hasta El cuervo blanco (2012), híbrido entre ensayo y biografía novelada sobre la vida y obra del importante gramático Rufino José Cuervo (1844-1911), las reflexiones de Vallejo en torno a la gramática son centrales para su proyecto literario y su concepción del rol de la literatura en el mundo contemporáneo.

La obra de Vallejo - en particular La virgen de los sicarios y El cuervo blanco - investiga la relación entre la gramática, el lugar de enunciación del intelectual que reflexiona sobre el lenguaje y el ejercicio del poder. El proyecto "gramatical" de Vallejo es contradictorio y seductor: mientras el provocador protagonista de La virgen invoca a Cuervo y defiende la reflexión lingüística propia de la gramática en un país en que esta ha sido un saber constitutivo de los proyectos excluyentes de nación, la novela celebra el carácter cambiante de la lengua y defiende el lugar de la literatura frente a otros saberes y prácticas que no pueden dar cuenta de cómo el uso del lenguaje determina las relaciones sociales. Mientras El cuervo blanco celebra la genialidad de Cuervo examinando su obsesivo proyecto de clasificación del castellano, las reflexiones gramaticales, filológicas y semánticas del autor prueban que el "genio rebelde, cambiante, caprichoso" (299) de la lengua no se puede encerrar en una gramática. Teniendo en cuenta la centralidad de lo que para Vallejo es la "falsa ciencia" y el "embeleco" (67) de la gramática en la obra del autor, examinaremos la manera en que este articula una profunda crítica contra la sistematización de la lengua, que produce una defensa de la literatura como el lugar donde se pone en escena la vida del lenguaje y se reflexiona sobre el mundo. 
La complejidad estilística y temática de La virgen ha suscitado múltiples lecturas, entre las cuales sobresale el interés por examinar el lugar del intelectual y su relación con la violencia que atestigua y produce. O'Bryen examina la locación ambivalente de la agencia narrativa en las novelas de Vallejo a partir de la forma en que sus narradores cuasiautobiográficos, que no pueden ser confundidos con el autor, producen el espacio urbano mediante su deambular por Medellín, revelando tanto la reproducción de prácticas espaciales hegemónicas y violentas como su cuestionamiento. En un agudo análisis sobre el proyecto intelectual anticristiano de Vallejo, Hoyos demuestra que la herejía es el principio que gobierna la impronta crítica de varios de sus textos y que produce una refutación sistemática de la existencia del Dios cristiano y una denuncia de la manera en que la religión católica está íntimamente relacionada con un orden político que perpetúa la violencia y la miseria en Colombia.

El presente artículo busca contribuir a esta veta crítica que localiza en su obra importantes aportes críticos. En este sentido, nos distanciamos de aquellas lecturas que ven en La virgen la celebración del desastre que impide que la novela se comprometa con postura crítica alguna (Jaramillo), un texto que expresa de modo transparente el supuesto discurso racista o neofascista de su autor (Polit Dueñas) o una novela que aboga por el retorno a un orden agrario y exclusionista heredado de la Colonia (Suárez). Dichas lecturas que resaltan la impronta reaccionaria, fascista, nihilista o apocalíptica de la novela tienden a pasar por alto que la contradicción constituye el motor de la obra de Vallejo y la invitación que seduce a sus lectores. Suelen ignorar las múltiples máscaras y posiciones que ocupa el autor para construir su provocadora persona literaria en diversos escenarios y las contradicciones evidentes entre sus afirmaciones sobre la naturaleza ficticia de su obra, el uso de narradores semiautobiográficos y la repetida referencia a su imposibilidad de escribir más que en la primera persona.

La virgen es el relato de viaje de Fernando, un escritor homosexual que regresa después de muchos años de exilio a una Medellín transformada por las guerras libradas alrededor del narcotráfico, por el fracaso de los violentos e inacabados procesos de modernización y por la desigual inserción de una ciudad como Medellín en el orden capitalista global. En sus recorridos por la ciudad caótica y letal acompañado de los dos jóvenes sicarios de los que se enamora, Fernando reflexiona sobre la posibilidad de escribir y relatar en medio de la ciudad violenta, y cataloga, analiza y termina adoptando las expresiones populares y los juegos de lenguaje que utilizan los jóvenes marginales, jerga que para muchos letrados en un país de larga tradición de gramáticos implicaría usos erróneos, incorrectos e impuros de la lengua. Fuera de hacer referencia a su oficio de escritor, Fernando 
se define a sí mismo como "el último gramático de Colombia" (30), "en este que fuera país de gramáticos siglos ha" (20), e invoca en numerosas reflexiones sobre el lenguaje y la semántica a Rufino José Cuervo, a quien llama un "viejo amigo [...] a quien frecuenté en mi juventud" (20). De forma paralela, en El cuervo blanco, que el autor introduce como un santoral de Cuervo, este sostiene que el trabajo de Cuervo "dejó una gran huella en mî" (26) y "definió mi vida" (47). Autor y narrador se construyen en diversos textos y discursos de Vallejo como herederos de un saber que fue central para la construcción del orden político colombiano desde la Independencia.

\section{La limpieza y esplendor de los gramáticos}

$\mathrm{Al}$ posicionarse como el último de los gramáticos colombianos, el narrador de La virgen evoca una importante tradición de letrados de fines de siglo XIX y comienzos del Xx, cuyo conocimiento y erudito manejo de la lengua castellana y del latín estuvo íntimamente ligado a la actividad política. Deas y von der Walde han sugerido que el estudio de la lengua y la gramática, junto con el ejercicio de la escritura, durante décadas fue el requisito para ejercer el poder político en Colombia, al señalar los efectos de estas prácticas letradas en la consolidación de un orden político conservador, hispanista y católico legitimado por el Estado y la ley que buscó amurallar a la nación de los cambios que traía consigo la modernidad. La gramática, como ciencia que abogaba por la pureza del lenguaje y la articulación de leyes permanentes y perdurables para el uso de la lengua, fue uno de los saberes hegemónicos que determinaron el acceso al poder en Colombia, con importantes consecuencias políticas.

El gramático colombiano más importante de esta época marcada por la institucionalización de la ciudad letrada fue Rufino José Cuervo, cuyo fantasma puebla los textos y alocuciones de Vallejo desde que publicó su tratado sobre el lenguaje literario, en 1983. Como uno de los filólogos y gramáticos de la lengua española más reconocidos del mundo a finales del siglo XIX, momento de la consolidación del hispanismo como disciplina, Cuervo editó y comentó la famosa Gramática de Andrés Bello (1874), fue autor de las Apuntaciones críticas sobre el lenguaje bogotano (1872), de un Catecismo de urbanidad (1883) y del inacabado Diccionario de construcción y régimen de la lengua española que Vallejo analiza en profundidad en El cuervo blanco. Cuervo se lamentó con pesimismo de lo que consideraba la inminente pérdida de la unidad del castellano que localizaba en una etapa similar a la transición en el Medioevo entre el latín vulgar y las diversas lenguas romances. En sus Apuntaciones críticas sobre el lenguaje bogotano, tratado comparativo entre el habla local y el castellano de España, que ya para 1885 se 
había convertido en la obra de erudición más popular en la Colombia de la época, Cuervo observó las diferencias entre las hablas locales desde los parámetros de lo que él consideraba el esplendor lingǘstico de la España del Siglo de Oro, que implantó en América su proyecto colonial. En El cuervo blanco, Vallejo explica el propósito de las Apuntaciones de la siguiente manera:

Por la época de la gramática latina que escribió con Miguel Antonio Caro, Cuervo empezó sus Apuntaciones críticas sobre el lenguaje bogotano, un libro que Colombia amó y que decidió mi vida. Parecía un libro de provincialismos o de dialectología pero no, era algo más, mucho más, un libro normativo: su fin era enseñarle a hablar bien a Colombia, y Colombia, hasta donde pudo y le dio su cabecita loca, aprendió, convirtiéndolo de paso en el árbitro del idioma. (47)

Cuervo catalogó los errores y desviaciones que alejaban a los bogotanos del buen uso de la lengua, lamentó la pérdida de "la copiosa y la más castiza habla de nuestros padres" y localizó el buen uso del idioma en un segmento social definido por "las personas cultas", que se diferenciaban del "vulgo" que erraba en el uso de la lengua y se desviaba de la norma (xii). Para Cuervo, "En Bogotá, como en todas partes, hay personas que hablan bien y personas que hablan mal, y en Bogotá, como en todas partes, se necesitan y se escriben libros que, condenando los abusos, vinculen el lenguaje culto entre las clases elevadas, y mejoren el chabacano de aquellos que, por la atmósfera en que han vivido, no saben otro" (x). En este sentido, el proyecto proscriptivo y prescriptivo de Cuervo se relacionaba con la producción de un tipo de ciudadanía: estaba ligado a un proyecto social de entendimiento basado en unas jerarquías particulares de la lengua que estipulaban el uso "correcto" del lenguaje a partir de una norma proveniente de la lengua literaria de Cervantes. Este "bien hablar", que estaba íntimamente ligado a una clase social "culta", constituía el requisito para tener acceso a la ciudad letrada y al poder (von der Walde, 76 ).

El intelectual y político que comprendió de forma más explícita las dimensiones políticas de la regulación de la lengua fue Miguel Antonio Caro, gramático, filósofo, poeta, miembro con Cuervo de la recién fundada Academia de la Lengua, presidente de Colombia (1894-1898) y uno de los artífices del orden político conservador que definió el Estado centralista, autoritario y católico que rigió la vida colombiana del siglo XX. Junto con otros presidentes conservadores posteriores, como José Manuel Marroquín y Miguel Abadía Méndez, autores también de extensos tratados lingüísticos, diccionarios y gramáticas, el ímpetu catalogador y prescriptivo de Caro revela la profunda conexión entre actividad política y 
políticas de la lengua en la historia colombiana (Deas, 31). Como señala von der Walde, en sus numerosos escritos Caro reparó en la relación entre lengua y orden político sustentando en la gramática un discurso político y religioso antimoderno que produjo una idea de nación definida por la tradición española y católica (76). "El uso correcto de la lengua", sugiere von der Walde con respecto a Caro "remite no solo al orden gramatical. En la lengua se consignan el orden divino, la moral y por tanto la conducción de los pueblos" (77). Para Caro la "limpieza" lingüística del castellano provenía del mayor grado de civilización del lenguaje que él localizaba en la España colonizadora, cuyo esplendor estaba atado a un proyecto moral católico. Como sugiere Deas "La lengua permitía la conexión con el pasado español, lo que definía la clase de república que estos humanistas [de fines de siglo XIX] querían" (47).

Durante la colonización española en América, época que sirvió de parámetro del esplendor cultural para los gramáticos colombianos, el lenguaje operó como sistema simbólico para transmitir la doctrina cristiana. De dicha concepción surgen las prácticas amalgamadas bajo el concepto de reducción, que han estudiado Cummins y Rappaport, entre las que se encuentra el ordenamiento de las sociedades americanas a través de una serie de gramáticas de lenguajes indígenas que buscaban ordenar un mundo considerado caótico y que produjeron una jerarquía cultural en la que las lenguas de origen latino tenían primacía. En términos espaciales, se estableció una estrecha relación entre la letra y el espacio urbano, ya que la organización de gramáticas indígenas venía de la mano de la organización de ciudades y pueblos desde el espacio de una plaza que irradiaba el poder eclesiástico a las diferentes regiones periféricas rurales (Cummins y Rappaport 176). La producción de documentos legales, eclesiásticos y literarios durante la época colonial coincidió con prácticas espaciales que instituyeron el poder sobre los cuerpos indígenas. Así como se pretendía reducir (ordenar, hacer razonar) a los indígenas al conocimiento de Dios, la planeación urbana fue también una instancia de ordenamiento íntimamente ligada a la escritura. Los funcionarios públicos de la Colonia, responsables tanto de sumarios como de gramáticas, inscribían el espacio social en documentos, a través de lo que Cummins y Rappaport han llamado un espacio alfabético (176). La reflexión lingüística del protagonista gramático de La virgen y su circulación por el espacio de Medellín y sus iglesias nos remite también a esa historia colonial que encontró continuidad en la Colombia de fines de siglo XIX.

Aunque estos gramáticos-políticos colombianos del siglo XIX compartieron la preocupación de Andrés Bello con la unidad del castellano frente a la diversidad de usos del lenguaje y los dialectos y jergas utilizados en las nuevas 
repúblicas hispanoamericanas, estos entendieron la relación entre lenguaje y política de forma distinta. No abogaban por el derecho de los americanos a participar en la formación de una lengua común que ampliara el castellano peninsular, ni consideraban el lenguaje elemento central para el proyecto liberal de integración comercial hispanoamericana. Von der Walde demuestra cómo estos esfuerzos por fijar el castellano correcto y la doctrina moral católica se tradujeron en la construcción de un proyecto hegemónico de nación "excluyente de las mayorías mestizas del país y [que] deja de lado también la existencia de más de ochenta familias de lenguas indígenas en el territorio. Los saberes letrados, la fe católica, el hispanismo serán dominio de unos pocos que legitimarán con ello su derecho al poder" (79). En este contexto se enmarca la Constitución de 1886, que rigió la vida colombiana durante más de un siglo, diseñada por Caro y otros letrados interesados en el estudio de la lengua. Esta buscó centralizar un país fragmentado desmontando el modelo de un Estado laico propuesto por anteriores gobiernos liberales, para volver a restituir el poder de la Iglesia en el ámbito educativo y social. Como señala Hoyos, diversos textos de Vallejo aluden precisamente a este trasfondo histórico que aportó a la consolidación de una identidad nacional íntimamente ligada a lo católico, y en el proceso intentan examinar los vínculos de esa colombianidad cristiana con la historia de sus violencias. Al alejarse de los modelos propuestos por los gramáticos decimonónicos y sus aliados, la Constitución de 1991 buscó romper con el matrimonio entre Iglesia y Estado bajo una impronta liberal y multicultural, reconociendo por primera vez la pluralidad cultural y lingüística de la nación. En los años posteriores a la firma de esa nueva Constitución que intentó poner fin, al menos en la letra, al imperio de los gramáticos, surge la novela de Vallejo, en la que un protagonista gramático quiere revisar la relación entre lengua, violencia y nación.

\section{De la reducción a la redacción}

A la luz del legado de los gramáticos, von der Walde sugiere que la literatura colombiana es parcial o totalmente antiletrada, pues "Buscar cómo viven, hablan y piensan los que están fuera de la ciudad letrada implica una exclusión de ella. Los escritores mismos en muchos sentidos son también unos excluidos y gradualmente irán excluyendo todo aquello que defienden los letrados de la ciudad amurallada tras diccionarios, gramáticas y libros de oración" (80). En La virgen, los recorridos del gramático que se deslumbra por el lenguaje de los sicarios con el que los letrados de la llamada "Atenas suramericana" de antaño se habrían horrorizado, dan lugar precisamente a una radiografía de estas tensiones y choques en la vida del lenguaje que determinan, tanto el ámbito político como el espacio de 
la literatura. Bakhtin nos recuerda que una de las dimensiones fundamentales de la vida social surge de las tensiones existentes en una sociedad entre un lenguaje unitario - aquel que las fuerzas que buscan centralizar la cultura presentan como lenguaje oficial-y un lenguaje vivo marcado por sus fuerzas centrífugas, es decir, por la mezcla conflictiva de códigos que constantemente buscan descentralizar y minar ese esfuerzo unificador (271). La política se localiza en aquellos espacios en los que los lenguajes chocan y evolucionan en un ambiente de heteroglosia social. Para Bakhtin la novela es el género que posibilita la puesta en escena de dichos choques y allí es donde radica su dimensión política.

La construcción del narrador como gramático en La virgen alude, en primera instancia, a un reconocimiento del lugar central que ocupa el lenguaje en la consolidación del orden político y en la construcción de jerarquías sociales, como bien lo entendieron Caro y Cuervo. Sin embargo, mediante una serie de estrategias narrativas, temáticas y formales la novela coopta la figura del gramático para cuestionar su autoridad discursiva y el alcance de su esfuerzo prescriptivo y en el proceso crea una defensa de la literatura como el lugar donde se pone en escena la naturaleza movediza y esquiva del lenguaje. Lander ha sugerido que el narrador de La virgen demuestra una confianza inquebrantable en el estatus que ocuparon los letrados hispanoamericanos hasta mediados del siglo XX y que precisamente esto demuestra su irrelevancia en el Medellín violento al que llega después del exilio (78). Polit-Dueñas subraya el lugar hegemónico que ocupa el narrador al ser un sujeto blanco de clase alta que expresa su jerarquía absoluta sobre los sicarios. Dichas lecturas se complican frente a la atención que el propio narrador arroja sobre su dificultad de ordenar el espacio, de recordar, de hilar los acontecimientos y de utilizar el "bien hablar" que Cuervo elogia en las personas cultas y en la literatura misma.

Aunque el protagonista se posiciona al comienzo de la novela como el heredero del legado de limpiar, fijar y dar esplendor a la lengua, sus reflexiones sobre la dificultad de escribir, de hilar la "colcha deshilachada de retazos" (30) que es Medellín pueblan el texto. "Señor procurador", dice Fernando en su interpelación más emblemática, evocando al abogado poeta de La vorágine, que denuncia en varias cartas la violencia fronteriza a un funcionario del gobierno, "yo soy la memoria de Colombia y su conciencia y después de mí no sigue nada. Cuando me muera, aquí sí que va a ser el acabose, el descontrol. Señor Fiscal General o Procurador o como se llame, mire que ando en riesgo de muerte por la calle" (21). Este lamento del protagonista frente a un Estado que él mismo critica de corrupto e inoperante revela la conciencia de que el letrado ya no ejerce el rol sagrado de la manipulación de los signos que para Rama definió el primer siglo de historia 
de la Hispanoamérica independiente. Esta afirmación resuena en la época en que se publica la novela cuando los llamados violentólogos, los académicos que desde las ciencias sociales adquirieron un rol central en la interpretación de los dramas sociales de la nación, se convierten en los intelectuales del Estado (Villaveces 311). La ansiedad del narrador respecto a su lugar de enunciación dentro de la comunidad nacional al comienzo del texto inaugura un cuestionamiento sobre las posibilidades de la literatura de producir sentido de las crisis históricas contemporáneas y sobre el rol mnémico del escritor frente a ellas.

Una memoria organizada supondría una gramática organizada, un uso adecuado de pasado, presente y futuro; una concordancia de órdenes temporales, de frases completas, una conjugación que no falla. Pero este autoproclamado gramático suele ser el primero en tener dificultad para utilizar los tiempos verbales de manera apropiada, porque su memoria está cansada: "Después de los dos sicarios de Aranjuez con moto ¿quién siguió?" (47), pregunta, cuestionando su propia autoridad de historiador, así como la transparente narración cronológica que privilegian los medios para contar los eventos cotidianos. "¿Pero qué les estaba diciendo...?" (8), pregunta perdido en su propio relato. "Pero estoy anticipando, rompiendo el orden cronológico e introduciendo el desorden" (30), se lamenta cuando intenta describir el espacio laberíntico de las comunas. A veces ni siquiera encuentra el verbo para terminar la frase.

El desorden sintáctico y cronológico de este gramático contrasta con lo que para Barthes es la maestría que el científico, el lingüista, el jurista o el gramático claman sobre el acto de relatar y de construir la frase. Barthes sugiere que el potencial lúdico del texto literario radica precisamente en la manipulación de la jerarquía sintáctica del texto del experto, y que allí es donde la literatura es capaz de producir una crítica epistemológica (50). En el laberinto de los callejones de Medellín por los que camina Fernando invocando a Cuervo, los intentos de sujetar la realidad al tenue orden de la redacción provocan una sintaxis fragmentada y una narración interrumpida. La novela se distancia así de los discursos académicos y científicos y de lo que sería, en palabras de Cuervo, del "uso respetable" de la lengua por parte de los hombres cultos, cuyo paradigma sería la frase completa.

La dificultad de ordenar el lugar y sus sucesos se revela también en términos narratológicos a partir de la ausencia de capítulos, índices y demarcaciones que hacen de la novela una compilación de episodios sueltos en la que no se conjugan vidas tanto como se van hilando episodios desconectados. De hecho, La virgen se puede describir utilizando la misma imagen de la colcha de retazos que el narrador menciona en algún momento para hablar de Medellín. Allí se combinan pequeñas narraciones de eventos sueltos, comentarios gramaticales, análisis lingüísticos, 
reflexiones sobre la topografía urbana, denuncias contra diversas instituciones y figuras públicas, análisis históricos que no respetan el orden cronológico, interpelaciones al lector y constantes devaneos sobre la relación entre atestiguar y participar en la violencia. Llama la atención la diferencia que marca La virgen frente a la crónica que sobre la misma convulsionada época elabora García Márquez en Noticia de un secuestro (1996), relato cuya trama depende de una voz autorial en control capaz de transcribir de forma ordenada y económica los testimonios de una época por parte de los protagonistas de las altas esferas del poder político afectadas por la violencia del narcotráfico. ${ }^{1}$ En sus constantes alusiones a la dificultad de la redacción, el gramático de Vallejo se va revelando como un impostor que se aleja del impulso prescriptivo de sus antecesores y que, al distanciarse del tratado, del ensayo, del diccionario, hila un texto heteroglósico en el que caben todo tipo de discursos, que es, para Bakhtin, lo que define a la novela.

\section{El esplendor del lenguaje coloquial}

Fuera de situarse formalmente en las costas opuestas de una narración organizada y de una trama eficiente, las reflexiones en torno al lenguaje usado en la Medellín de fines de siglo Xx le permiten a la novela competir y diferenciarse del periodismo, la crónica judicial y los relatos académicos provenientes de las ciencias sociales que ostentan el monopolio de la narración histórica en épocas contemporáneas y han sido centrales para construir las violencias como objeto de interés público. Anunciar que la novela está de vuelta para mapear la ciudad violenta, encargarse de los muertos cotidianos, trazar los atracos y robos y preguntarse por la vida cotidiana implica defenderla frente a la primacía de los medios masivos. En este sentido, la atención al lenguaje le permite al texto diferenciarse de la narración eficiente y rápida de los eventos diarios que sale de "un televisor furibundo transmitiendo telenovelas, y entre telenovela y telenovela las alharacosas noticias: que hoy mataron a fulanito de tal y anoche a tantos y a tantos" (11). Mientras critica el "desinflamiento semántico" (51) que producen los medios cuando narran la historia y se encarga de definir el lenguaje que se usa en las calles de la ciudad, el narrador arremete contra las ciencias sociales, por su

1 Con la excepción de algunas referencias a la función de la prensa escrita, la radio y la mediación de los medios en el conflicto entre el narcotráfico y el Estado, el texto de García Márquez pasa de largo cualquier reflexión sobre "la carpintería confidencial del libro" que el autor construyó para evitar "una narración laberíntica" (7). Vallejo, quien ha criticado la obra de García Márquez, entre otras razones, por su confianza total en la tercera persona, escribe una novela que alude explícitamente a la carpintería de su novela y que produce deliberadamente una narración laberíntica. 
incapacidad de atender a la dimensión lingüística de la vida social en sus análisis sobre la violencia.

$\mathrm{Al}$ referirse a la comuna nororiental de la ciudad el narrador cuestiona la mirada gramatical tradicional que plantea la existencia de un orden lingüístico y social frente al cual la lengua viva de las comunas sería el emblema de la corrupción provocada por el desorden:

Como cuando un muchacho de allí dice: "Ese tombo está enamorado de mî". Un "tombo" es un policía, ¿pero "enamorado"? ¿Es que es marica? No, es que lo quiere matar. En eso consiste su enamoramiento: en lo contrario. Cualquier sociólogo chambón de esos que andan por ahí analizando en las "consejerías para la paz" concluiría de esto que al desquiciamiento de una sociedad se sigue el del idioma. iQué va! Es que el idioma es así, de por sí ya es loco.(56)

La crítica a los sociólogos, muchos de los cuales se convirtieron a finales de siglo XX en intelectuales de un Estado que para el narrador ha perdido toda legitimidad, sugiere una defensa de la reflexión lingüística como punto de partida para entender la historia colombiana. Si "todo el problema de Colombia es una cuestión de semántica" (49), la novela está allí para examinar el lenguaje vivo, aclarar los malentendidos y trazar la forma en que la vida tensa del lenguaje incide en el ámbito social y sus violencias. La mejor manera de acceder a un momento histórico particular, nos indica el gramático, requiere conocer la lengua que en ese momento se habla, observar las cosas que activamente se hacen con las palabras, comprender el lenguaje cambiante y movedizo que precede y describe la crisis. A diferencia de los medios que con su "cacareo" solo dan cuenta de los cuerpos que caen y de las ciencias sociales que desdeñan el lugar central que ocupan los actos de habla en la vida social, la novela se posiciona como un texto más relevante para abordar el desastre y recordar la historia.

En su propuesta de atención a la interlocución y a los actos de habla de sujetos considerados amenazantes y extraños radica la defensa del género novelístico y el ímpetu ordenador de la novela. Comprender los descoyuntamientos sociales de Medellín está íntimamente ligado al análisis de los "vocablos y giros nuevos, feos, para designar ciertos conceptos viejos"(23) que utilizan sus jóvenes sicarios, aquel lenguaje que Víctor Gaviria ha llamado "un lenguaje que fluye contra la normalidad, contra el lenguaje de los libretistas y el lenguaje literario, o contra la economía de la eficiencia y la comunicación" (230). ${ }^{2}$ La virgen mapea

2 Cuando en la década de los noventa Vallejo en la novela, Víctor Gaviria en el cine y Alonso Salazar en el testimonio rastrearon este lenguaje de los jóvenes de las comunas conocido como 
las cosas que los jóvenes de las comunas de Medellín hacen con las palabras, resemantizándolas, inventando nuevos vocablos, revitalizando los viejos, demostrando la vitalidad de un lenguaje urbano particular marcado por un tiempo y unas circunstancias sociales específicas. El proceso de definir las palabras de los muchachos de las comunas posiciona inicialmente al narrador como un experto que busca comprender y definir para los lectores la jerga cotidiana de esos jóvenes e indica una polisemia que desafía el diccionario. Al dar cuenta de los usos locales de la lengua y contextualizarlos en su escenario de uso, la novela coopta así la función del diccionario, a la vez que lo supera inaugurando una reflexión sobre la vida del lenguaje en medio de la situación violenta. En el proceso revela las fuerzas centrífugas del lenguaje que para Bakhtin definen cualquier época histórica, así como la futilidad misma de la reducción producida por el diccionario general que pasa por alto aquello que no hace parte de un lenguaje mayoritario. ${ }^{3}$ Más aún, el hecho de que la trama de la novela sea sobre el proceso mismo de examinar el lenguaje, nos alerta respecto al lugar de enunciación desde donde se produce el conocimiento de la lengua y cuestiona la supuesta objetividad del diccionario. En efecto, el hecho de que Fernando esté enamorado de sus sicarios complica desde el comienzo no solo la relación entre el gramático y el poder hegemónico que este históricamente representaría, sino la ilusión de objetividad del experto o la distancia depurada que predica el escritor o editor del testimonio en la literatura testimonial.

En sus reflexiones sobre la gramática y el lenguaje, Wittgenstein plantea que "los problemas filosóficos surgen cuando el lenguaje se va de vacaciones" (19), subrayando el potencial que tienen los juegos cotidianos con la lengua para provocar la reflexión crítica. En La virgen el rastreo de los juegos de lenguaje de los jóvenes de las comunas da lugar a importantes reflexiones que amplían la investigación lingüística hacia dimensiones éticas y políticas. En un momento

parlache, este todavía hacía parte de una subcultura juvenil específica de Medellín. Décadas después, gran parte de esta jerga ha influenciado de forma definitiva otros lenguajes juveniles en Colombia hasta el punto que muchas de sus expresiones han sido ampliamente adoptadas en la cultura popular y constituyen un elemento central de las tramas de series de televisión y películas sobre violencia urbana y criminalidad.

3 En las últimas décadas surgen en Colombia diversos diccionarios especializados que buscan catalogar los lenguajes relacionados con la violencia con diversos propósitos políticos. Véase, por ejemplo, el Diccionario de parlache en el que Castañeda y Henao buscan demostrar la creatividad del lenguaje juvenil urbano y contribuir a las reflexiones históricas y culturales sobre la realidad nacional. En El lenguaje del hampa y del delito, Arias Echeverri utiliza el diccionario para definir las palabras que usan los criminales en cárceles y escenarios jurídicos, para que su procesamiento y disciplinamiento sea más eficiente. 
emblemático del texto, caminando en medio de la ciudad letal, el protagonista presencia un atraco que termina en un asesinato. Alexis, el primer amante de Fernando, interpreta los hechos. El gramático se posiciona como intérprete de segundo grado para explicar al lector lo sucedido:

"El pelao debió de entregarle las llaves a la pinta esa", comentó Alexis, mi niño, cuando le conté el suceso. [...] Y yo me quedé enredado en su frase soñando, divagando, pensando en don Rufino José Cuervo y lo mucho de agua que desde entonces había arrastrado el río. Con "el pelao" mi niño significaba el muchacho; con "la pinta esa" el atracador; y con "debió de" significaba "debiô" a secas: tenía que entregarle las llaves. Más de cien años hace que mi viejo amigo don Rufino José Cuervo, el gramático, a quién frecuenté en mi juventud, hizo ver que una cosa es "debe" solo y otra "debe de".... Y "debe" a secas significa que se tiene que, como cuando digo: "La ley debe castigar el delito". ¡Pero cuál ley, cuál delito! Delito el mío por haber nacido y no andar instalado en el gobierno robando en vez de hablando. El que no está en el gobierno no existe y el que no existe no habla. iA callar! (20)

Hablando a borbotones desde un lugar de enunciación distinto al del Estado, el gramático se enreda en el habla del sicario que contamina la lengua con voces locales o nuevos giros, alejándose de la obsesión prescriptiva de Cuervo, para desenredarla. Analizar el rompimiento de las reglas lingüísticas y el significado del léxico particular de Alexis da lugar a una reflexión sobre otra serie de reglas que están íntimamente conectadas con la gramática, que son las del sistema jurídico y el orden simbólico en general. Las relaciones entre lenguaje y ley se revelan, entre otras cosas, cuando Fernando analiza las diferencias entre el "debe de" (prescripción moral) y el "debe" (orden), que Alexis ha colapsado en la frase. ¿Qué pasa en el ámbito social cuando se confunden estos conceptos, cuando la dimensión normativa y ética se desdeña bajo la lógica de la necesidad?

La lógica clasificadora del diccionario y el ímpetu prescriptivo de la gramática también se complican en el texto a través de la reflexión del narrador sobre las dimensiones performativas de los actos de habla que nos remite a la densidad ética y política del uso del lenguaje. Al detenerse tanto en la semántica como en la fuerza que tienen los actos de habla, más allá de su contenido literal, como sucede, por ejemplo, con su análisis del término hijueputa, el gramático reflexiona sobre cómo se hacen cosas con las palabras, aquello que Austin llamaría las dimensiones ilocucionarias y perlocucionarias del lenguaje que trascienden su dimensión descriptiva (locucionaria) y se relacionan con los efectos que producen las palabras en el mundo (afirmar, cualificar, apabullar, callar a otro en el caso 
de "hijueputa"), un elemento fundamental de las relaciones entre los sujetos y de las relaciones de poder.

Mientras que la actitud de los gramáticos decimonónicos hacia el estudio de la lengua está marcada por la ansiedad con respecto a su transformación histórica y su divergencia de un canon hispanista que se define como parámetro, el gramático de Vallejo se instala en el corazón de la contaminación y la convierte en el campo privilegiado de la literatura. Mientras que Cuervo insiste en sus Apuntaciones en que las palabras de origen peninsular deben siempre preferirse a las voces locales americanas (indígenas, africanas, campesinas o regionales), el autoproclamado gramático no busca sancionar pues, como explica, "carezco de reparos idiomáticos... todo me gusta" (46). Así como ya en Don Quijote, obra de la época idealizada por Caro y Cuervo y a la que Vallejo hace referencia en varios de sus textos, aparece el lenguaje cambiante de una época específica, La virgen repara en la maleabilidad de la lengua, en su diversidad de registros y su potencial estético, celebrando su esplendor. Al alejarse de la proscripción, la atención de la novela al lenguaje de sujetos tradicionalmente pensados como peligrosos, violentos y abyectos desde el espacio antaño sagrado de la literatura complica las distinciones entre jerga y "buen hablar" que han definido los proyectos de nación en Colombia.

Ya en Logoi, su tratado sobre el lenguaje literario, el novelista examina todo un léxico, una morfología, una sintaxis y una retórica que apartan al lenguaje literario del hablado. Sin embargo, aunque la literatura aparece allí como el lugar por excelencia donde se ejerce el dominio de las fórmulas y de los procedimientos gramaticales y retóricos, Vallejo concluye su tratado anunciando algo que aplicará más adelante en sus novelas: "el lenguaje coloquial con su desorden y su encadenamiento fortuito de las ideas", sugiere, "pasa de los diálogos al relato y se apodera de la novela entera" (536). De hecho, el uso de la segunda persona a lo largo del texto, que resulta de la interpelación del gramático a los lectores o a otros personajes sin recurrir al diálogo, hace hincapié en la invasión de la lengua hablada al espacio de la novela. Junto con el vaivén de tiempos verbales que pueblan el relato, esta alternancia entre primera y segunda persona instala a la novela en la problemática de la interlocución, que depende de las categorías gramaticales de persona, tiempo y voz.

En El cuervo blanco Vallejo critica la gramática occidental por depender en gran parte de la lengua literaria para sostener su proyecto prescriptivo y por ignorar que existen importantes diferencias entre la lengua hablada y el idioma escrito (en términos sintácticos, de vocabulario, etc.) (217). Como herederos de esa tradición, Bello y Cuervo utilizan las obras literarias clásicas españolas para 
dictar la norma gramatical de una lengua viva muy diversa socialmente. En $L a$ virgen, el narrador gramático cuestiona esa jerarquía postulada por sus antecesores. Mientras que José Eustasio Rivera en La vorágine (1924) busca evitar que el lenguaje rural de los llanos orientales que fascina a su protagonista poeta se tome el texto y lo reduce en un glosario para establecer su distancia del lenguaje literario, el narrador de La virgen deshace cualquier intento de limpieza literaria al contaminarse de la jerga de las comunas, rompiendo la distancia entre "vulgo" y "gente culta" elaborada por Cuervo. En vez de proscribirlo o contenerlo, la narración demuestra la forma en que la escritura del letrado se va impregnando de la lengua que Cuervo llamaría "plebeya", hasta el punto en que Fernando termina la novela interpelando al lector como "parcero", una emblemática palabra de las comunas que quiere decir amigo y nos entrena para utilizar ese registro. Al buscar colapsar esa distancia entre lenguaje literario y hablado, el gramático está socavando la base misma de la gramática tradicional, cuyos parámetros dependerían, en palabras de Cuervo de "las obras de los más afamados escritores y en el habla de la gente de esmerada educación" (xiv). En una movida profundamente antigramatical, el novelista construye una novela que, contaminada por el habla cotidiana de sujetos marginales, se rehúsa a servir como parámetro de la corrección. Su narrador se conmueve con el lenguaje movedizo y cambiante, al tiempo que plantea una interrupción del proyecto catalogador de sus abuelos gramáticos.

Las reflexiones lingüísticas de la novela resuenan con las investigaciones sobre la filosofía del lenguaje de Wittgenstein, que desmantelan la gramática prescriptiva para proponer que el lenguaje no es una serie de signos estáticos y fijos, sino que está sujeto a cambios constantes y a las travesuras que contra los códigos gramaticales se cometen en el uso cotidiano de la lengua. Para Wittgenstein, la gramática está situada en la actividad regular y cotidiana de un lenguaje utilizado pública y socialmente y de los juegos que con él se hacen. Esta determina la relación entre los objetos (nombrados arbitrariamente) no a partir de reglas fijas y naturales, sino a partir de señales (que el austriaco a veces llama "postes de señalización" o ejemplifica con la imagen de las reglas generales para jugar ajedrez) que expresan las normas para el entendimiento básico y para los juegos a los que constantemente los sujetos someten al lenguaje. Si tradicionalmente la gramática buscaba determinar las reglas de un uso sintáctico y semántico "correcto", Wittgenstein la piensa más bien como una red amplia e interconectada de reglas que determinan de forma muy general lo que se entiende y lo que no se entiende, expresando un posible orden, pero no el orden final, fijo o natural.

La metáfora topográfica de Wittgenstein encaja de manera muy precisa con el proyecto de Vallejo. El filósofo arguye que entre más de cerca examinamos 
el lenguaje corriente, aparece de forma más patente el conflicto entre este y sus requisitos. "Hemos llegado al hielo resbaloso en el que no hay fricción y, en cierto sentido, las condiciones son ideales, pero también, precisamente por ello, somos incapaces de caminar. Queremos caminar: entonces necesitamos fricción. ¡De vuelta al terreno agreste!" (46; mi traducción). Al proveer una topografía de la ciudad y un mapa de su lenguaje que excede el ordenamiento colonial y republicano, la novela se instala en este "terreno agreste" de la calle donde se hacen cosas con el lenguaje de todos los días. ${ }^{4}$ En este terreno surge, para Wittgenstein, la filosofía, y para Vallejo, la novela.

En medio de la evidente subversión del ordenamiento gramatical tradicional que plantea La virgen en varios planos, la novela nos presenta, a la vez, irritantes contradicciones que suponen un complejo desafío crítico. Una de las tensiones más evidentes presentes en el texto radica en que, mientras el protagonista interpela constantemente a sus lectores, la interlocución dentro del universo narrativo de la novela se cancela a partir de la fuerza física de las balas. De constatar los disparos y describir la violencia cotidiana y su lenguaje, el protagonista se transforma en cómplice o instigador de los tiros con que los sicarios silencian a otros. La novela mapea así una violencia epistémica que radica en la supresión de la diferencia ejemplificada en un protagonista que, para poder construir su subjetividad, localiza a otros sujetos en una relación radicalmente negativa frente a sí mismo. De hecho, a medida que el texto se va impregnando de jerga, el narrador se va transformando en el autor intelectual de los asesinatos diarios de sus amantes (Lander 78). A medida que avanza la trama, Fernando va revelando sus posturas intolerantes - misóginas, racistas y clasistas - que se relacionarían con un orden social patriarcal, jerárquico y exclusionista que ha sido central para diversos proyectos de nación, y así traza una relación entre la violencia de las balas y este tipo de discurso. ${ }^{5}$ Los antecesores gramáticos de Fernando construyeron

4 El gramático de La virgen camina por las calles laberínticas en las que se usa el lenguaje coloquial mientras registra esas otras curvas, los giros de frases y las figuras que se apartan del lenguaje "correcto" de Cuervo y Caro. La confluencia en la novela de reflexión lingüística con topografía evoca la idea de De Certau de que el espacio geométrico producido por arquitectos y urbanistas comparte el estatus de "significado correcto" que los gramáticos y lingüistas construyen a nivel de la lengua normativa para comparar el desvío del lenguaje cotidiano. "En la realidad", dice De Certeau, "este significado 'correcto' sin rostro no se puede encontrar en el uso corriente, ya sea verbal o pedestre; es simplemente una ficción producida por un uso que es también particular" (100; mi traducción). Para una discusión más profunda sobre los cruces entre topografía y gramática en la novela véase Ospina.

5 Para una crítica de la construcción del espacio peligrosamente masculino de la novela, véase el estudio de Pratt. Desarrollo el tema del borramiento del género femenino de la conjugación 
un proyecto intelectual que "operó tan eficazmente como sistema de exclusión de sus contrincantes políticos que la letra no pudo funcionar como espacio para la negociación no violenta de los conflictos sociales o políticos" (81). La pregunta que la novela abre es hasta qué punto puede Fernando desligarse de esta herencia y hasta qué punto la perpetúa.

Algunos críticos se enfocan en esta dimensión violenta del discurso del protagonista para localizar los aportes críticos del texto. Para Lander, la novela deconstruye la función regulatoria del intelectual, cuyo rol en anteriores épocas históricas habría sido la de árbitro, pedagogo u ordenador (de la ley, de la lengua, etc.). La conversión de Fernando en el que dirige los actos de sus sicarios revela la responsabilidad histórica del intelectual en la creación y perpetuación de las fracturas y violencias sociales colombianas (78). Pensando en el lugar de los lectores a quien Fernando interpela como amigos o aliados, Franco sugiere que la misoginia y el racismo del protagonista letrado nos fuerza a preguntarnos si somos cómplices de esta violencia epistémica y qué tan profunda es nuestra identificación con esta ideología fascista (225). O’Bryen sugiere abandonar los intentos de localizar el discurso "fascista" del personaje en su autor o simplificar la complejidad crítica de la novela reduciéndola a este tipo de discurso, invitándonos a reparar en las posibilidades interpretativas del texto como ficción.

Como hemos notado anteriormente, esta es una novela sobre la vida del lenguaje, un texto volcado a notar su polisemia y la inestabilidad de significantes y significados. En este sentido, el texto mismo nos entrena a tener en cuenta las estrategias textuales que lo constituyen como texto de ficción. En vez de leer las disquisiciones reaccionarias del protagonista como mimesis, sugiere O'Bryen, debemos enfrentarnos a ellas como semiosis (201). Este demuestra que muchas de las afirmaciones "fascistas" de Fernando se vacían o debilitan a través de los deliberados juegos con el lenguaje, la repetición constante, el uso del humor, entre otras, que se despojan de su fuerza y de sus afirmaciones de contener la verdad.

Coincidimos con Hoyos en que la coherencia de un proyecto intelectual en la obra de Vallejo - como el que cuestiona el entramado discursivo católico que constituye la colombianidad - "no conduce a resolver las contradicciones dentro del texto", pues "un elemento central de su poética es escenificar la contradicción [...] adoptar al mismo tiempo las voces más contradictorias" (120). En vez de buscar solucionar las contradicciones de la novela, vemos en la oscilación de su narrador entre la crítica a un saber determinante para la construcción de la

y de la reinscripción de las relaciones homosexuales dentro de un panorama heterosexual normativo en la novela, en Ospina. 
nación y el discurso intolerante que en muchos casos la ha sustentado la apertura de diversas preguntas sobre la vida social del lenguaje y su relación con el panorama violento. ${ }_{\mathrm{i}}$ Puede la letra contribuir a ese espacio de negociación que en el texto aparece truncado? ¿Puede el lenguaje, con sus reglas generales básicas, como diría Wittgenstein, proveer una red de las ataduras, nexos, vínculos y códigos que posibiliten el contrato social? La novela nos exige una lectura que, en vez de buscar síntesis apacibles, reconozca la urgencia de estas preguntas éticas, lingüísticas, políticas.

\section{El fantasma de Cuervo}

En la época de las celebraciones del bicentenario de la Independencia de Colombia y del aniversario de la muerte de Rufino José Cuervo, Vallejo retorna la gramática para reflexionar sobre lenguaje y cultura y examinar la conflictiva historia nacional desde fines de siglo XIX. En su libro El cuervo blanco (2012), Vallejo se adentra en la vida y obra de Cuervo a partir de una investigación de miles de documentos que incluyen cartas, diarios, artículos, así como los tratados de lexicografía, gramática y filología del autor. El fantasma de Cuervo se aparece también por estas épocas en discursos y artículos del escritor en los que denuncia el olvido público en el que ha caído el gramático y elogia su vida dedicada exclusivamente a la reflexión del lenguaje y sus usos. ${ }^{6}$ En ellos, el escritor ha invocado a Cuervo para lamentarse de que "el lenguaje está tan indefenso como los animales" y sostiene que la mayoría de las personas, incluidos importantes novelistas como Vargas Llosa, cometen errores con la lengua que él, como experto en gramática, sí es capaza de depurar. Este rol de discípulo de Cuervo se suma, a veces de manera contradictoria, a la construcción multifacética que Vallejo ha hecho de su figura autorial como enfant terrible, iconoclasta, crítico acérrimo del Estado, de la Iglesia católica, la religión y el nacionalismo, defensor de los animales, crítico de la reproducción y la heteronormatividad, etc.

El cuervo blanco es una obra densa y extensa, híbrido entre biografía novelada, ensayo, reconstrucción histórica de una época y novela en la primera persona sobre un escritor que busca a su maestro fallecido un siglo atrás para canonizarlo. A diferencia de la organización formal del texto historiográfico, el tratado lingüístico e, incluso, la biografía convencional, El cuervo blanco está anclado en las costas de la novela: es un texto desordenado, repetitivo y deliberadamente largo, que carece de capítulos o secciones e irrespeta la cronología. Es una obra

6 Véase, por ejemplo, sus discursos "El extraño país de Rufino José Cuervo" (2006) y "En el centenario de la muerte de Rufino José Cuervo" (2011), que dio en Bogotá en la última década. 
circular que empieza y termina con la muerte del gramático; pero se adentra a su vez en otras épocas históricas. Al poner el relieve en la imposibilidad de utilizar la tercera persona, el autor sostiene que reconstruye la vida de Cuervo como "novelista que inventa" (95), lo cual sugiere que la escritura histórica depende de la construcción narrativa y no puede asumirse como objetiva. ${ }^{7}$ Pero aunque el uso de la primera persona localiza al texto dentro del territorio de la novela, este está cruzado por extensos análisis sobre lengua y cultura que lo acercan también al ensayo. El trabajo archivístico que implica un retorno a los espacios emblemáticos de la ciudad letrada, le permite al texto reconstruir la conflictiva historia de Colombia de fines de siglo XIX, en particular la vida política y cultural de sus élites, relatar el surgimiento de los presidentes gramáticos, las tensiones partidistas y las guerras y sublevaciones que se libraron, "de las que hoy nadie se acuerda" (112). Al articular un nuevo relato sobre la vida de Cuervo, el texto de Vallejo complica la institucionalización de su figura por parte del Estado y la academia que suele pensar a Cuervo de manera conjunta con Caro y los políticos gramáticos de la "Atenas suramericana".

¿Cómo encaja la "canonización" que Vallejo busca hacer de Cuervo en $E l$ cuervo blanco con el cuestionamiento de la gramática articulado en La virgen? Nos encontramos aquí con otra movida contradictoria típica de los textos vallejianos. Aunque Vallejo describe su proyecto textual como una hagiografía, su libro articula una profunda crítica del ímpetu ordenador de la gramática que desarrolla aún más a fondo la noción de la fuerza cambiante del lenguaje y la importancia de examinarlo en sus usos cotidianos y contemporáneos ya expuesta en La virgen. Explicando el interés normativo de los proyectos de Bello y de Cuervo, el autor pregunta " ¿Pero cuál norma? ¿La de hoy o la de ayer? ¿La de Colombia o la de México? ¡Cuál norma puede haber en un idioma que tiene mil años y está repartido en veinte países díscolos, cada uno con la suya!"(217). Su crítica de las premisas de Cuervo y otros gramáticos de su época sirven para demostrar cómo las normas que intenta establecer la gramática son arbitrarias y limitadas frente a la vitalidad y diversidad de usos del español. Al denunciar que "la gramática no se ocupa de los contextos" (290), Vallejo despliega su experticia demostrando que él está ahí para suplirlos y, a su paso, revelar su superioridad frente a sus maestros.

Los gramáticos, desde Panini y Dionisio de Tracia, han creído que pueden dar cuenta de su idioma con un acto de prestidigitación metiendo las infinitas

7 A pesar de la naturaleza híbrida de este texto, que dificulta encapsularla únicamente dentro del campo de la ficción, El cuervo blanco ha sido catalogado como novela. Fue uno de los libros considerados para el Premio Nacional de Novela del Ministerio de Cultura de Colombia, en 2014. 
palabras en unas cuantas categorías artificiosas de lo que llaman morfología, y en unas cuantas construcciones de lo que llaman sintaxis. Imposible. El genio del idioma no se deja meter en una botella, como los de las Mil y una noches. Inmenso y escurridizo, se burla de las categorías y terminologías de los gramáticos, y de paso de la lógica porque no es lógico sino eficaz. Voy a poner unos cuantos ejemplos, de muy diverso orden, para ilustrar el fracaso de los colegas de don Rufino (267-8).

En largos fragmentos, Vallejo somete las categorías gramaticales a un riguroso cuestionamiento a través de ejemplos diversos que prueban su vasto conocimiento de la lengua, de sus categorías gramaticales y de las diversas variantes del español actual de España y las Américas. El autor demuestra cómo las categorías sintácticas establecidas por los gramáticos son demasiado estrechas y prueba los diversos usos que las exceden. Tal es el caso del adjetivo que se convierte en gerundio; de la oscilación de muchos verbos entre la dimensión transitiva, intransitiva y de significación absoluta que socava la rigidez de esas categorías; de la ausencia de una categoría gramatical que dé cuenta de lo que él llama el proverbo; entre muchos otros ejemplos. Esta crítica a la gramática viene de la mano de un profundo cuestionamiento del diccionario como tecnología de sistematización semántica y sintáctica de las palabras que solo las captura cuando están muertas (279). Vallejo critica, además, a la Real Academia de la Lengua por operar bajo una perspectiva iberocéntrica frente al español americano y omitir un diverso vocabulario de uso en las Américas. ${ }^{8}$ Este rechazo profundo al lugar central que ocupa el español de España en los proyectos de sistematización lingüística le permite al autor alejarse aún más del proyecto decimonónico de los gramáticos que celebraban las raíces hispánicas de la lengua y de la nación. En lo que termina siendo un tratado antigramatical, Vallejo concluye que la diversidad del español con sus "miles y miles de caprichos cambiantes: fonéticos, ortográficos, semánticos, morfológicos, sintácticos" (273) hacen del proyecto de limpiar y fijar la lengua un esfuerzo fútil e imposible. El idioma, concluye Vallejo, "no se deja sistematizar, ni en gramáticas ni en diccionarios, y el río que un día logras meter en un caño mañana se crecerá y se saldrá de caño y de madre" (285).

Pero si la gramática es "una pseudociencia [...] un ejercicio de la mente ociosa, una pestilencia de las neuronas" (227), ¿en qué consiste entonces la

8 En diversos artículos y entrevistas Vallejo ha criticado la desmesurada centralidad de la cultura ibérica en la reflexión semántica del español, arguyendo que España es un país más de las decenas de países hispanohablantes y que, por consiguiente, no debe determinar la norma. Véanse, por ejemplo, algunos de sus ensayos en Peroratas. 
"hagiografía" que hace Vallejo de Cuervo y de su obra? En el Diccionario de construcción y régimen de la lengua castellana que Cuervo no alcanzó a terminar (para 1893 había publicado dos mil páginas de lo que eran solo los dos primeros tomos), Vallejo localiza un proyecto monumental, genial y sin precedentes que pone en duda todos los cimientos de la gramática misma. A diferencia de las gramáticas de sus antecesores, que intentaban hacer caber el lenguaje movedizo e infinito dentro de unas pocas categorías morfológicas y sintácticas, Cuervo buscó describir las funciones y los problemas gramaticales de miles de palabras clave del español en sus diversas acepciones. El resultado fue una obra que trasciende los parámetros de diccionarios y gramáticas exponiendo sus límites. Explica Vallejo: Con el Diccionario de construcción y régimen de la lengua castellana lo que él pretendía era apresar el río caudaloso de este idioma, que venía del año 1000 cuando se bifurcó del latín, y que arrastraba en sus aguas torrentosas mucha basura recogida de aquí y de allá de siglo en siglo aunque eso sí, mezclada con unas cuantas joyas. Cuervo en su desmesura lo quería todo: la basura y las joyas. [...] la ambición del desmesurado Rufino José Cuervo era meter en un diccionario todas las frases pronunciadas y escritas por los millones y millones de hispanohablantes que habían vivido en los novecientos años que lleva de existencia el castellano. (237)

El intento inicial de Cuervo de examinar las características combinatorias de las palabras en sus usos normales y correctos lo llevó a enfrentarse a su naturaleza movediza, obligándolo a rastrear las modificaciones de sus significados, a determinar su etimología y sus cambios ortográficos. Para ello debió establecer la historia del uso de cada término, remontándose hasta el romance medieval. El resultado de este proyecto histórico monumental fue un "tratado de morfología, de sintaxis, de etimología, de fonética, de ortografía y de semántica" que "tiene que ver además con la historia del idioma" (278). Y también una especie de historia literaria, pues recoge el uso de las palabras por parte de los autores canónicos de la lengua castellana, al tiempo que produce un diccionario de citas y autoridades.

Para Vallejo la genialidad de este mal llamado Diccionario radica en que deshizo el andamiaje epistemológico y discursivo de donde surgía, pues terminó probando, a través de sus intentos de sistematización, que la enrevesada historia del español y de su literatura no es sino el relato de sus cambios constantes. De hecho, el objeto de estudio de Cuervo probó ser tan movedizo y las transformaciones de las palabras por rastrear tan complejas que el gramático solo alcanzó a publicar miles de páginas que llegaron hasta la letra $\mathrm{D}$ y a redactar la entradas hasta la palabra empero, por lo que dejó inacabada la mayoría de una obra que 
fue completada solo hasta un siglo después por el Instituto Caro y Cuervo, en Bogotá. A pesar del gesto enciclopédico que dio aliento al proyecto, para Vallejo el tratado se convierte en un texto sobre la imposibilidad de la catalogación, pues pone en duda los intentos de fijar la lengua que ha estado en el centro de la historia cultural de España en las Américas, y en el centro de la vida política colombiana. " ¿Fracasó entonces Cuervo, como el común de los gramáticos, en su intento de apresar este idioma?", pregunta Vallejo, "Sí pero no. Con su diccionario-gramática atiborrado de decenas de miles de citas hizo ver como nadie que el idioma no es como el genio de Aladino que se deja encerrar en una botella, sino un genio rebelde, cambiante, caprichoso, que se sale de donde lo quieren meter y no lo agarra ni el loquero" (299).

La literatura en la que se basa Cuervo para aportar los ejemplos que sostienen su rastreo de cada palabra, es el artefacto en el que el río del lenguaje demuestra su fluir. Si por sus páginas cruza la lengua en toda su contingencia histórica, la literatura no sirve de parámetro desde el cual se determina la corrección lingüística, como se pone en escena en La virgen. En su discurso de celebración del centenario de la muerte de Cuervo, Vallejo sugiere que la genialidad de su tratado radicó en convertir el diccionario en gramática, y la gramática, en una obra de arte ("En el centenario de la muerte"). Quizás el horizonte estético al que se refiere Vallejo para hablar del Diccionario lo aporta precisamente la literatura: las numerosas citas literarias que van llenando cada entrada de Cuervo y revelando la naturaleza cambiante de cada palabra a lo largo del tiempo terminan por tomarse el tratado entero y mirar su ímpetu catalogador y sus intentos de contención. La literatura, en su capacidad de capturar la historia de una época, invade la gramática, se toma el texto enciclopédico y lo trastoca desde adentro. También lo hace desde afuera, pues la escritura novelística de Vallejo encapsula el tratado de Cuervo y lo desmantela. La redacción supera aquí a la reducción. Como en La virgen, en el Diccionario cualquier intento de catalogación termina transformándose en literatura. Como en La virgen, la reflexión sobre el lenguaje solo puede hacerse desde la novela.

Algunas cartas de Cuervo escritas al final de su vida revelan su toma de conciencia de lo que él llama su "herejía gramatical". Cuervo acepta que la gramática es deficiente, porque su nomenclatura se aleja de los usos concretos de la lengua: "Impuesta la nomenclatura a una cosa tan fluida y movediza como el lenguaje, se encuentra uno a menudo con que los hechos no casan ya con aquella pauta, y no halla nombre ni cajilla en que acomodarlos. [...] las líneas rectas, las figuras geométricas puede decirse que no existen en la naturaleza, son puras abstracciones" (citado en Vallejo 295). Podríamos localizar en este cuestionamiento de las 
abstracciones producidas por la gramática, con el que está de acuerdo Vallejo esa defensa de la producción estética y literaria que ya se había comenzado a articular en La virgen. En este contexto, El cuervo blanco, da continuidad al proyecto de celebrar la literatura como el lugar por excelencia por donde pasa la vida del lenguaje y donde suceden sus reflexiones. La literatura se convierte así en una de las prácticas que socavan los grandes sistemas de conocimiento occidentales, que para De Certeau definen, entre otras cosas, el espacio urbano y la circulación de los cuerpos, y que incluyen las abstracciones, mapas y normas de gramáticos, cartógrafos, retóricos, académicos y científicos.

Fuera de defender el rol de la literatura en un texto literario sobre una gramática que se torna literatura, Vallejo localiza en la biografía de Cuervo un modelo de autonomía intelectual que lo distancia de los presidentes letrados políticos, como Miguel Antonio Caro, que tradicionalmente ostentaron el poder político en Colombia. De hecho, El cuervo blanco cuestiona el relato histórico que localiza a Caro y a Cuervo dentro de una misma tradición, al hacer hincapié en la diferencia en sus trayectorias vitales y, en última instancia, en las direcciones a la que llevaron sus reflexiones lingüísticas. Aunque Vallejo es consciente de la inserción de Cuervo en diversos regímenes discursivos que sostenían el poder en su época - su fervor católico y su interés por prescribir la norma lingüística son ejemplos de ello-, el autor resalta su autodidactismo, su rechazo a participar en la política convencional de su época y su exilio voluntario a Europa de donde nunca regresó como pruebas de una autonomía intelectual distanciada del ejercicio de la política convencional. Habiendo ya canonizado en obras anteriores a los poetas José Asunción Silva y Porfirio Barba Jacob como figuras ejemplares de esa búsqueda de autonomía estética y crítica, subrayando su rechazo a ser voceros de una colectividad social o nacional, Vallejo posiciona a Cuervo dentro de ese mismo linaje intelectual que se deslinda del matrimonio entre política y literatura que rigió la vida intelectual colombiana hasta bien entrado el siglo XX. ${ }^{9}$

La figura de Cuervo le sirve a Vallejo para articular una visión de la autonomía de la cultura en la que la actividad intelectual es superior en la escala de valores a la actividad pública, que es precisamente lo que plantearon los modernistas hispanoamericanos en la misma época en la que el gramático escribió su Diccionario. En el contexto de las reflexiones públicas sobre la construcción de la

9 Véase Barba facob el mensajero y Almas en pena, chapolas negras, las biografías noveladas de Barba Jacob y Silva en las que Vallejo reconstruye a través de minuciosas pesquisas la vida de estos dos poetas colombianos, una marcada por la migración y los viajes, y la otra, por el suicidio. 
nación que surgen durante la celebración del Bicentenario de la Independencia, esta biografía de Cuervo complica cualquier apropiación oficial del gramático como prohombre ejemplar que habita el panteón de los grandes hombres de la patria. Vallejo imagina a través suyo la posibilidad de ejercer la acción crítica desde coordenadas desligadas de la política convencional y de las estructuras del poder hegemónico religioso, estatal y heteronormativo.

La indignación que Vallejo expresa en novelas y discursos frente al empobrecimiento de la lengua en su uso cotidiano, frente a su anglización y a los errores que cometen presidentes, escritores, políticos y el común de la gente, viene acompañada de sus constantes lecciones pedagógicas sobre reglas gramaticales básicas que garantizarían un uso adecuado del lenguaje común. Así, en una clásica movida dialéctica vallejiana, la crítica al ímpetu normativo de la gramática y a la fantasía de fijar un idioma muy amplio y cambiante no implica un llamado al desmantelamiento radical de todos los códigos del uso de la lengua o a la celebración de la arbitrariedad total de los signos. Más bien, podríamos leer en sus constantes lecciones sobre el uso adecuado de reglas gramaticales generales, con las que el autor se vuelve maestro, una defensa de un mínimo de códigos y reglas de juego compartidas que provean los nexos y los vínculos que posibilitan el contrato social. La herejía gramatical de Vallejo consiste en que socava las premisas lógicas y epistemológicas de un saber que ha servido para sustentar una ideología política y religiosa determinante para la conflictiva historia de Colombia, a la vez que usurpa para la literatura la responsabilidad de documentar el paso del río cambiante del lenguaje, adjudicándole la tarea de enriquecerlo de nuevo, de demostrar su esplendor y de reflexionar sobre el contrato social que este habilita. Despojada de los embelecos, la literatura documenta la accidentada, caudalosa, cambiante vida del lenguaje, y con ello la historia del mundo.

\section{Obras citadas}

Austin, J. L. How to do Things with Words. Cambridge,

Mass.: Harvard University Press, 1975.

Bakhtin, Mikhail. The Dialogical Imagination. Trad. Michael Holquist

y Caryl Emerson. Austin: Texas University Press, 2001.

Barthes, Roland. The Pleasure of the Text. Trad. Richard Miller.

New York: Farrar, Straus and Giroux, 1989.

Cummins, Tom y Joanne Rappaport. "The Reconfiguration of Civic and

Sacred Space: Architecture, Image, and Writing in the Colonial Northern

Andes". Latin American Literary Review 26.52 (1998): 174-200. 
Cuervo, Rufino José. Apuntaciones críticas sobre el lenguaje bogotano. Bogotá: Arnulfo M. Guarín, 1872.

Deas, Malcolm. Del poder y la gramática y otros ensayos sobre historia, política y literatura colombianas. Bogotá: Tercer Mundo, 1993.

De Certeau, Michel. The Practice of Everyday Life. Trad. Steven Rendall. Berkeley: University of California Press, 1988.

Franco, Jean. The Decline and Fall of the Lettered City: Latin America in the Cold War. Cambridge: Harvard University Press, 2002.

Gaviria, Víctor. "Violencia, representación y voluntad realista" [entrevista]. Espacio urbano, comunicación y violencia en América Latina. Ed. Mabel Moraña. Pittsburg, PA: Instituto Internacional de Literatura Iberoamericana, 2002.

Hoyos, Héctor. "La racionalidad herética de Fernando Vallejo y el derecho a la felicidad". Revista de Estudios Sociales 35 (2010): 113-122.

Jaramillo, Alejandra. Nación y melancolía: narrativas de la violencia en Colombia (1995-2005). Bogotá: Instituto Distrital de Cultura y Turismo, 2006.

Lander, María Fernanda. "The Intellectual Criminal Discourse in Our Lady of the Assassins by Fernando Vallejo". Discourse: Fournal for Theoretical Studies in Media and Culture 25.3 (2003): 76-89.

O'Bryen, Rory. "Representations of the City in the Narrative of Fernando Vallejo". Fournal of Latin American Cultural Studies 13.2 (2004): 195-204.

Ospina, María. "Evocar y convocar: violencia y representación en la narrativa colombiana contemporánea". Tesis doctoral. Universidad de Harvard, 2009.

Pratt, Mary Louise. "Tres incendios y dos mujeres extraviadas: el imaginario novelístico frente al nuevo contrato social". Espacio urbano, comunicación y violencia en América Latina. Ed. Mabel Moraña. Pittsburgh, PA: Instituto Internacional de Literatura Iberoamericana, 2002. 91-105.

Polit-Dueñas, Gabriela. "Sicarios, delirantes y los efectos del narcotráfico en la literatura colombiana". Hispanic Review 74 (2006): 119-42.

Rama, Ángel. La ciudad letrada. Hanover, NH: Ediciones del Norte, 1984.

Suárez, Juana. Sitios de contienda: producción cultural colombiana y el discurso de la violencia. Madrid: Iberoamericana-Vervuert, 2010.

Vallejo, Fernando. Almas en pena chapolas negras. Bogotá: Alfaguara, 1995.

-. Barba facob el mensajero. Bogotá: Alfaguara, 1991.

-. "En el centenario de la muerte de Rufino José Cuervo". Discurso en la Biblioteca Luis Ángel Arango. Bogotá. 3 de febrero de 2011.

-. El cuervo blanco. Bogotá: Alfaguara, 2012.

-. "El lejano país de Rufino José Cuervo". Conferencia en F-10, Festival de El Malpensante, Bogotá, 28 de octubre de 2006. 
-. La virgen de los sicarios. Bogotá: Alfaguara, 1994.

-. Logoi: una gramática del lenguaje literario. México:

Fondo de Cultura Económica, 2005.

-.Peroratas. Bogotá: Alfaguara, 2013.

Villaveces, Santiago. "The Crossroads of Faith: Heroism and Melancholia in the Colombian "Violentologists" (1980-2000)". Cultural Agency in the Americas.

Ed. Doris Sommer. Durhman: Duke University Press, 2006. 305-325.

von der Walde Uribe, Erna. "Limpia, fija y da esplendor: el letrado y la letra en

Colombia a fines del siglo XIX". Revista Iberoamericana 178.9 (1997): 71-83.

Wittgenstein, Ludwig. Philosophical Investigations. Trad G. E. M.

Anscombe. Oxford: Blackwell Publishers, 1998. Impreso. 